\title{
openheart Polymer-free sirolimus-eluting stents in a large-scale all-comers population
}

\author{
Florian Krackhardt, ${ }^{1}$ Viktor Kočka, ${ }^{2}$ Matthias W. Waliszewski, ${ }^{3}$ Andreas Utech, ${ }^{4}$ \\ Meik Lustermann, ${ }^{5}$ Martin Hudec, ${ }^{6}$ Martin Studenčan, ${ }^{7}$ Markus Schwefer, ${ }^{8}$ \\ Jiangtao Yu, ${ }^{9}$ Myung Ho Jeong, ${ }^{10}$ Taehoon Ahn, ${ }^{11}$ Wan Azman Wan Ahmad, ${ }^{12}$ \\ Michael Boxberger, ${ }^{3}$ André Schneider, ${ }^{13}$ Matthias Leschke ${ }^{13}$
}

\begin{abstract}
- Additional material is published online only. To view please visit the journal online (http://dx.doi.org/10.1136/ openhrt-2017-000592)
\end{abstract}

To cite: Krackhardt $F$, Kočka V, Waliszewski MW., et al. Polymer-free sirolimus-eluting stents in a large-scale allcomers population. Open Heart 2017:4:e000592. doi:10.1136/ openhrt-2017-000592

Received 11 January 2017 Revised 9 March 2017 Accepted 21 March 2017

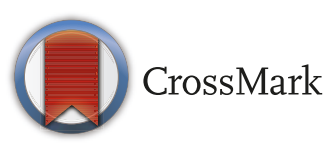

For numbered affiliations see end of article.

Correspondence to Dr Florian Krackhardt; Florian. Krackhardt@charite.de

\section{ABSTRACT}

Objective The objective of this study was to assess the safety and efficacy of a polymer-free sirolimus coated, ultrathin strut drug-eluting stent (PF-SES) in an unselected patient population with a focus on acute coronary syndrome (ACS). Furthermore, stable coronary artery disease (CAD) with short ( $\leq 6$ months) versus long (>6 months) dual antiplatelet therapy (DAPT) were also studied.

Methods Patients who received PF-SES were investigated in an unselected large-scale international, single-armed, multicenter, 'all comers' observational study. The primary endpoint was the 9-month target lesion revascularisation (TLR) rate, whereas secondary endpoints included the 9-month major adverse cardiac events (MACE) and procedural success rates. A priori defined subgroups such as patients with ACS, diabetes, lesion subsets and procedural characteristics relative to DAPT were investigated.

Results A total of 2877 patients of whom 1084 had ACS were treated with PF-SES $(1.31 \pm 0.75$ stents per patient). At 9 months, the accumulated overall TLR rate was $2.3 \%$ (58/2513). There was no significant difference between ACS and stable CAD (2.6\% vs $2.1 \%, p=0.389)$. However, the overall MACE rate was $4.3 \%(108 / 2513)$ with a higher rate in patients with ACS when compared with the stable CAD subgroup (6.1\%, $58 / 947$ vs $3.2 \%, 50 / 1566, p<0.001)$. Conclusions PF-SES angioplasty is safe and effective in the daily clinical routine with low rates of TLR and MACE in an unselected patient population. Our data are in agreement with prior clinical findings that extended DAPT duration beyond 6 months do not improve clinical outcomes in patients with stable CAD (ClinicalTrials.gov Identifier NCT02629575).

Trial registration number NCT02629575.

\section{INTRODUCTION}

Drug-eluting stents (DES) have greatly reduced the need for repeat revascularisation despite studies revealing that first-generation DES were associated with stent thrombosis (ST) rates that were less favourable when compared with bare-metal stents. ${ }^{1}$

The theoretical advantage of new coating technologies such as bioabsorbable polymers or non-polymer coating and the potential patient benefit of a shortened

\section{KEY QUESTIONS}

What is already known about this subject?

- Sirolimus-coated drug-eluting stents can deliver a sufficient drug dose from a polymer and nonpolymer stent coating.

- Safety and efficacy for a sirolimus-probucol coating was already demonstrated in the ISARTEST 5 trial with long follow-up in diabetics and in patients with ST elevation myocardial infarction.

What does this study add?

- Our data suggest that well-known cardiovascular and lesion morphological risk factors, such as vessel diameter, lesion length and B2/C lesions, do not seem to impact the clinical results in an all-comers setting after polymer-free sirolimuseluting stenting.

- To date, this study is the largest 'all comers' registry in 2877 patients dedicated to the routine use of ultrathin-strut, polymer-free sirolimusprobucol coated stents, which can be safely and effectively used with very favourable rates of target lesion revascularisation (TLR) and major adverse cardiac events (MACE).

- Our data are in agreement with other large studies that patients who were not able to receive antiplatelet preloading in all-comers patients or extended dual anti-platelet therapy (DAPT) beyond 6 months in patients with stable coronary artery disease (CAD) do not have higher rates of TLR or MACE at 9 months.

How might this impact on clinical practice?

- Considering the ensemble of individual patient risk factors, in particular, for bleeding and early ST, a shortened DAPT of less than 6 months can be justified in patients with stable CAD.

dual-antiplatelet therapy (DAPT) may herald a new milestone in DES development. This, in turn, may enable patients to undergo other non-coronary treatments with a reduced risk of bleeding.

Currently, there are polarised opinions regarding the length of DAPT which range from an extended DAPT duration beyond 12 months with more favourable long-term 
clinical outcomes ${ }^{2}$ to a greatly shortened DAPT duration. ${ }^{3}$ The polymer-free matrix of the investigational device in this large-scale study consists of sirolimus and its matrix builder probucol which was initially studied in the ISARTEST 5 trial comparing a polymer-free sirolimus-eluting stent (PF-SES) to a zotarolimus-eluting stent (ZES) ${ }^{4}$ with similar safety and efficacy.

The objective of the study was to assess the safety and efficacy of PF-SES for the treatment of 'real-world' de novo and restenotic lesions in native coronary arteries and coronary bypass grafts.

\section{METHODS}

\section{End points and definitions}

The international ISAR 2000 all-comers registry (ClinicalTrials.gov Identifier NCT02629575) prospectively enrolled patients in Europe and Asia. The study protocol was approved by all relevant ethics committees prior to patient recruitment. The primary endpoint was the 9-month target lesion revascularisation (TLR) rate, whereas secondary endpoints were the 9-month major adverse cardiac events (MACE) rate, the in-hospital MACE rate and the corresponding rates of myocardial infarction (MI) and TLR (coronary artery bypass grafting and re-PCI (percutaneous coronary intervention). Cardiac death was only defined inhospital, whereas the all-cause death rate was used to define MACE at 9 months (MI, TLR, inhospital cardiac death and all deaths post discharge). The Academic Research Consortium (ARC) criteria $^{5}$ were used to define acute/subacute stent thrombosis.

Renal insufficiency was defined with a glomerular filtration rate $\left(\right.$ GFR) of $<90 \mathrm{~mL} / \mathrm{min} / 1.73 \mathrm{~m}^{2}$ with a cut-off GFR rate for mandatory dialysis of $<15 \mathrm{~mL} / \mathrm{min} / 1.73 \mathrm{~m}^{2}$. Severe tortuosity had to meet the angulation criterion of $>45^{\circ}$.

\section{Centres}

Patients were prospectively enrolled in 26 Asian (South Korea and Malaysia) and 36 European (Czech Republic, France, Germany, Slovakia and Spain) cardiac centres (see online supplementary appendix I).

\section{MATERIALS}

PF-SES (Coroflex ISAR, B. Braun Melsungen, Melsungen\%20AG,\%20Germany) were implanted according to each institution's guidelines and in accordance with proper indications for national reimbursement. Briefly, the bare-metal backbone of the PF-SES has been investigated previously by Leschke $e t$ $a l,{ }^{6}$ whereas the sirolimus matrix coating was extensively studied in the ISAR-TEST 5 trial $^{4}$ with very favourable clinical outcomes up to 5 years ${ }^{7}$ and in various subgroups such as patients with ST-elevation myocardial infarction ${ }^{8}$ and diabetics. ${ }^{9}$ The polymer-free stent platform consists of a premounted, thin strut $(50 / 60 \mu \mathrm{m})$ cobalt-chromium stent whose abluminal surface only is sandblasted to permit a microporous surface for the polymer-free matrix consisting of sirolimus and probucol. The concentration of sirolimus is $1.2 \mu \mathrm{g} / \mathrm{mm}^{2}$ on the abluminal stent surface only. Sirolimus is the active antiproliferative drug, and probucol is an excipient controlling the release of the drug. Probucol mimics the function of a polymer by retarding the release of sirolimus. Non-clinical testing showed that traces of sirolimus or probucol can be detected beyond 8 weeks. Different from drug-coated polymer-free stents without an excipient, the release of sirolimus over time is comparable to polymer-coated DES. This matrix coating concept has been evaluated in the aforementioned clinical trials on a different stent platform (Yukon stent, Translumina, Hechingen, Germany). Non-inferiority of the polymer-free sirolimus-probucol coated stent has been demonstrated in comparison to the ZES. ${ }^{4-9}$ The device is available in lengths of $8-32 \mathrm{~mm}$ and has a crossing profile $(0.79-0.93 \mathrm{~mm})$.

\section{Inclusion and exclusion criteria}

Patients $\geq 18$ years of age with stable angina or objective proof of ischaemia or patients with acute coronary syndrome (ACS) had to meet the requirements forPCI. ${ }^{10}$ Single or multiple vessel stenting was allowed in de novo or restenotic lesions with reference diameters from 2.0 to $4.0 \mathrm{~mm}$.

\section{Procedural approach}

Femoral or radial vascular access was permitted with recommended introducer sheaths of at least $5 \mathrm{Fr}$ in diameter. Moreover, operators could predilate with a balloon catheter of their preference or chose direct stenting at their discretion. Intravenous heparin $(70 \mathrm{IU} / \mathrm{kg})$ was given to all patients and supplemented when required. If possible platelet aggregation inhibitor loading was recommended prior to the procedure according to the institutional preferences of the cardiac centre.

\section{Postprocedural medication}

Due to the international characteristic of this study, it was permissible to use various antiplatelet inhibition agents ( $\geq 6$ months) such as clopidogrel $75 \mathrm{mg} /$ day, prasugrel $10 \mathrm{mg} /$ day or ticagrelor $2 \times 90 \mathrm{mg} /$ day as recommended by the treating physician while acetylsalicylic acid $100-325 \mathrm{mg}$ / day was prescribed life long.

\section{Data collection}

A dedicated and established electronic data capture systemwas used, which immediately informed the investigator of data quality issues. This database was used in prior large-scale unselected patient cohorts. ${ }^{611}$ The accuracy of the data sets on a national level was verified by the national principal investigators in each country when the routinely performed web-based plausibility checks indicated discrepancies.

\section{Statistical analysis}

For all tests, the significance level $\alpha$ was 0.05 . The two-sided Fisher's exact test or the $\chi^{2}$ statistic was used whenever 
Table 1 Patient demographics

\begin{tabular}{|c|c|c|c|c|}
\hline Variable & All patients & Stable CAD & ACS & $\begin{array}{l}\text { p Value } \\
\text { Stable CAD vs ACS }\end{array}$ \\
\hline No of patients & 2877 & 1793 & 1084 & - \\
\hline No of lesions & 3254 & 2031 & 1223 & - \\
\hline No of DES used & 3858 & 2453 & 1405 & - \\
\hline Age (years) & $66.9 \pm 11.2$ & $67.9 \pm 10.2$ & $65.2 \pm 12.5$ & $<0.001$ \\
\hline Male gender, n (\%) & $2126(73.9)$ & $1311(73.1)$ & $815(75.2)$ & 0.221 \\
\hline Diabetes, n (\%) & $1090(37.9)$ & $708(39.5)$ & $382(35.2)$ & 0.023 \\
\hline Hypertension, n (\%) & 2107 (73.2) & $1362(76.0)$ & $745(68.7)$ & $<0.001$ \\
\hline Renal insufficiency, n (\%) & $161(5.6)$ & $108(6.0)$ & $53(4.9)$ & 0.200 \\
\hline Dialysis dependence, $\mathrm{n}(\%)$ & $48(1.7)$ & $35(2.0)$ & $13(1.2)$ & 0.127 \\
\hline Haemodialysis, n (\%) & $31(1.1)$ & $23(1.3)$ & $8(0.7)$ & 0.302 \\
\hline Peritoneal dialysis, $\mathrm{n}(\%)$ & $17(0.6)$ & $12(0.7)$ & $5(0.5)$ & \\
\hline STEMI, n (\%) & $472(16.4)$ & $0(0.0)$ & $472(43.5)$ & - \\
\hline NSTEMI, n (\%) & $612(21.3)$ & $0(0.0)$ & $612(56.5)$ & - \\
\hline \multicolumn{5}{|l|}{ Region, n (\%) } \\
\hline Europe & 2025 (70.4) & $1256(70.1)$ & 769 (70.9) & 0.612 \\
\hline Asia & 852 (29.6) & 537 (29.9) & $315(29.1)$ & \\
\hline
\end{tabular}

Bold values are statistically significant.

ACS, acute coronary syndrome; CAD, coronary artery disease; DES, drug-eluting stents; NSTEMI, non-ST segment elevation myocardial infarction; ST, stent thrombosis; STEMI, ST-elevation myocardial infarction.

applicable to evaluate dichotomous variables. Continuous variables were compared with the unpaired t-test or the Mann-Whitney U test in case the Shapiro-Wilk test revealed a strong deviation from a normal distribution.

On the basis of previously published results with a predecessor device, ${ }^{4}$ a literature value of $10.3 \%$ for TLR was assumed for comparison. A 9-month TLR rate of $6.0 \%$ was postulated for the investigational device in this study. It was determined that the one group $\chi^{2}$ test $90 \%$ power to detect the difference between the null hypothesis proportion, $\pi_{0}$, of $6.0 \%$ and the alternative proportion, $\pi_{A}$, of $10.3 \%$ when the sample size is 396 . With an expected follow-up rate of at least $80 \%$, a minimum of 495 patients would have to be recruited to reject the null hypothesis that the 9-month TLR rate is non-inferior to the assumed TLR rate of the ISAR-TEST 5 trial.

Statistical analyses were conducted with SPSS V.24.0, whereas the biometric estimate was calculated with nQuery/nTerim V.2.0.

\section{RESULTS}

Between November 2014 and December 2015, a total of 2877 patients were recruited to receive PF-SES. Patient demographics are detailed in table 1 . The rate of diabetes mellitus (DM) was $37.9 \%(1090 / 2877)$ in the overall population, whereas 1084 patients or $37.6 \%$ were treated for ACS. Dialysis-dependent patients amounted to $1.7 \%(48 / 2877)$ in the overall cohort. Most patients were recruited in Europe $(70.4 \%, 2025 / 2877)$ while the frequency of ACS between regions was not significantly different $(\mathrm{p}=0.612)$.

\section{Lesion morphologies}

Overall, 3254 lesions were treated with 3858 PF-SES (table 2) primarily for de novo lesions (96.7\%, $3146 / 3254)$. Significant differences in lesion characteristics between patients with stable coronary artery disease (CAD) and those with ACS were observed in the rates of thrombotic occlusions $(3.6 \%$ vs $24.5 \%$, $\mathrm{p}<0.001)$, thrombus burden $(7.6 \%$ vs $25.2 \%, \mathrm{p}<0.001)$, in-stent restenosis (ISR, $4.1 \%$ vs $2.0 \%, \mathrm{p}=0.002$ ) and the degree of stenosis $(85.0 \% \pm 10.7 \%$ vs $89.9 \% \pm 11.0 \%$, $\mathrm{p}<0.001)$. The average use of PF-SES was significantly higher in the non-ACS group $(1.36 \pm 0.79$ vs $1.29 \pm 0.67$, $\mathrm{p}=0.031)$. The technical success rate to implant the PF-SES was not different between groups $(98.4 \%$ vs $98.0 \%, \mathrm{p}=0.411)$.

\section{Comedication}

In terms of the preprocedural drug therapy (table 3), the new antiplatelet inhibitors prasugrel and ticagrelor were more frequently used in patients with ACS $(\mathrm{p}<0.001)$ Patients without preloading amounted to $10.5 \%$ $(302 / 2877)$ in the overall cohort. Postprocedural DAPT use was different between patient groups. Patients with stable CAD received more frequently clopidogrel $(80.9 \%$ vs $\left.51.7 \%, \mathrm{p}_{\text {group }}<0.001\right)$ and less often prasugrel $(5.0 \%$ vs $19.4 \%)$ and ticagrelor $(11.8 \%$ vs $26.7 \%)$ when compared with patients with ACS. 
Table 2 Lesion characteristics and procedural data

\begin{tabular}{|c|c|c|c|c|}
\hline Variable & All patients & Stable CAD & ACS & $\begin{array}{l}\text { p Value } \\
\text { Stable CAD vs ACS }\end{array}$ \\
\hline No of lesions & 3254 & 2031 & 1223 & - \\
\hline \multicolumn{5}{|l|}{ Target vessel, n (\%) } \\
\hline Left Anterior Descending (LDA) & $1374(42.2)$ & $846(41.7)$ & $528(43.2)$ & 0.835 \\
\hline Left Circumflex (LCX) & $863(26.5)$ & $543(26.7)$ & $320(26.2)$ & \\
\hline Right Coronary Artery (RCA) & $987(30.3)$ & $624(30.7)$ & $363(29.7)$ & \\
\hline Graft & $30(09.9)$ & $18(0.9)$ & $12(1.0)$ & \\
\hline \multicolumn{5}{|l|}{ Multivessel disease, $\mathrm{n}(\%)$} \\
\hline 1-vessel & $2676(93.0)$ & $1671(93.2)$ & $1005(92.7)$ & 0.850 \\
\hline 2-vessel & $187(6.5)$ & $113(6.3)$ & $74(6.8)$ & \\
\hline 3-vessel & $14(0.5)$ & $9(0.5)$ & $5(0.5)$ & \\
\hline Thrombotic occlusion, $\mathrm{n}(\%)$ & $373(11.5)$ & $73(3.6)$ & $300(24.5)$ & $<0.001$ \\
\hline Chronic total occlusion, n (\%) & $129(4.0)$ & $104(5.1)$ & $25(2.0)$ & $<0.001$ \\
\hline Thrombus burden, $\mathrm{n}(\%)$ & $463(14.2)$ & $155(7.6)$ & $308(25.2)$ & $<0.001$ \\
\hline Diffuse vessel disease, $\mathrm{n}(\%)$ & $1520(46.7)$ & $954(47.0)$ & $566(46.3)$ & 0.701 \\
\hline Calcification, $\mathrm{n}(\%)$ & $1020(31.3)$ & $657(32.3)$ & $363(29.7)$ & 0.112 \\
\hline Ostial lesion, n (\%) & $317(9.7)$ & $202(9.9)$ & $115(9.4)$ & 0.613 \\
\hline Bifurcations, n (\%) & $446(13.7)$ & $284(14.0)$ & $162(13.2)$ & 0.554 \\
\hline In-stent restenosis, n (\%) & $108(3.3)$ & $83(4.1)$ & $25(2.0)$ & 0.002 \\
\hline Severe tortuosity, n (\%) & $346(10.6)$ & $226(11.1)$ & $120(9.8)$ & 0.238 \\
\hline Saphenous vein graft, $\mathrm{n}(\%)$ & $37(1.1)$ & $20(1.0)$ & $17(1.4)$ & 0.291 \\
\hline AHA/ACC type B2/C lesion, n (\%) & $1819(55.9)$ & $1159(57.1)$ & $660(54.0)$ & 0.085 \\
\hline Reference diameter (mm) & $2.83 \pm 0.51$ & $2.84 \pm 0.48$ & $2.81 \pm 0.54$ & 0.118 \\
\hline Lesion length (mm) & $20.1 \pm 12.1$ & $20.5 \pm 13.1$ & $19.4 \pm 10.1$ & 0.011 \\
\hline Degree of stenosis $(\%)$ & $86.9 \pm 11.0$ & $85.0 \pm 10.7$ & $89.9 \pm 11.0$ & $<0.001$ \\
\hline Predilation, $\mathrm{n}(\%)$ & $1218(37.4)$ & $780(38.4)$ & $438(35.8)$ & 0.139 \\
\hline DESs used & 3858 & 2453 & 1405 & - \\
\hline DES per patient & $1.33 \pm 0.75$ & $1.36 \pm 0.79$ & $1.29 \pm 0.67$ & 0.031 \\
\hline DES diameter (mm) & $2.83 \pm 0.49$ & $2.83 \pm 0.46$ & $2.81 \pm 0.53$ & 0.129 \\
\hline DES length (mm) & $21.9 \pm 9.9$ & $22.1 \pm 10.5$ & $21.5 \pm 8.9$ & 0.115 \\
\hline DES inflation pressure (atm) & $14.0 \pm 3.0$ & $13.9 \pm 3.1$ & $14.1 \pm 2.9$ & 0.085 \\
\hline Final result stenosis (\%) & $1.8 \pm 6.4$ & $1.9 \pm 6.4$ & $1.7 \pm 6.5$ & 0.541 \\
\hline Overall technical success per stent, $\mathrm{n}(\%)$ & $3790(98.2)$ & $2413(98.4)$ & $1377(98.0)$ & 0.411 \\
\hline
\end{tabular}

ACC, American College of Cardiology; ACS, acute coronary syndrome; AHA, American Heart Association; atm, atmosphere; CAD, coronary artery disease; CX, circumflex; DES, drug-eluting stents; LAD, left anterior descending artery; RCA, right coronary artery.

The recommended duration DAPT (table 4) was significantly longer in patients with ACS ( $\left.p_{\text {group }}<0.001\right)$, for example, the percentage of patients who underwent 12 months of DAPT was $70.4 \%$ (763/1084) versus $42.4 \%$ (761/1793). The number of patients with unknown length of DAPT was considerable $(17.1 \%, 493 / 2877)$ in the total study population.

\section{Clinical results}

Inhospital events

Inhospital clinical MACE (table 5) was significantly higher in patients with ACS when compared with those with non-ACS $(2.8 \%$ vs $0.6 \%, \mathrm{p}<0.001)$, which were driven by
MI $(1.8 \%$ vs $0.3 \%, \mathrm{p}<0.001)$, cardiac death $(1.2 \%$ vs $0.2 \%$, $\mathrm{p}<0.001)$ and TLR $(0.8 \%$ vs $0.3 \%, \mathrm{p}=0.039)$.

Nine-month events

The follow-up rate for the entire cohort was $87.3 \%$ $(2513 / 2877) \cdot \chi^{2}$ statistics and t-tests revealed that the risk profile (demographic and lesion morphological) was not different between those patients with and without 9-month follow-up (see online supplementary appendix II). At 9 months, the primary endpoint TLR was not significantly different between both groups (ACS: $2.6 \%$ vs stable CAD: $2.1 \%, \mathrm{p}=0.389)$. However, the 9-month MACE rate was almost twice as high as in patients with ACS when compared 
Table 3 Periprocedural drug therapy

\begin{tabular}{|c|c|c|c|c|c|c|}
\hline Drug type & & Drug & All patients (\%) & Stable CAD (\%) & ACS (\%) & $\begin{array}{l}\text { p-Value } \\
\text { Stable CAD vs } \\
\text { ACS }\end{array}$ \\
\hline \multirow{9}{*}{ Pre-PCl } & APT & Clopidogrel & $1529(53.1)$ & 1061 (59.2) & $468(43.2)$ & $<0.001$ \\
\hline & & Prasugrel & $328(11.4)$ & $162(9.0)$ & $166(15.3)$ & \\
\hline & & Ticagrelor & $383(13.3)$ & $156(8.7)$ & $227(20.9)$ & \\
\hline & & Ticlopidine & $19(0.7)$ & $9(0.5)$ & $10(0.9)$ & \\
\hline & & Aspirin only & $316(11.0)$ & $205(11.4)$ & $111(10.2)$ & \\
\hline & & No preloading & $302(10.5)$ & $200(11.2)$ & $102(9.4)$ & \\
\hline & $O A C$ & All OAC & $54(1.9)$ & $40(2.2)$ & $14(1.3)$ & 0.072 \\
\hline & & VKA & $33(1.1)$ & $25(1.4)$ & $8(0.7)$ & 0.188 \\
\hline & & $\begin{array}{l}\text { NOAC, eg, } \\
\text { rivaroxaban }\end{array}$ & $21(0.7)$ & $15(0.8)$ & $6(0.5)$ & \\
\hline \multirow[t]{5}{*}{ Post-PCl } & APT & Clopidogrel & 2010 (69.9) & 1450 (80.9) & $560(51.7)$ & $<0.001$ \\
\hline & & Prasugrel & $300(10.4)$ & $90(5.0)$ & $210(19.4)$ & \\
\hline & & Ticagrelor & 501 (17.4) & $212(11.8)$ & $289(26.7)$ & \\
\hline & & Aspirin only & $28(1.0)$ & $16(0.9)$ & $12(1.1)$ & \\
\hline & & Unknown & $38(1.3)$ & $25(1.4)$ & $13(1.2)$ & \\
\hline
\end{tabular}

ACS, acute coronary syndrome; APT, antiplatelet therapy; CAD, coronary artery disease; NOAC, new oral anticoagulative; OAC, oral anticoagulatives; $\mathrm{PCl}$, percutaneous coronary intervention; VKA, vitamin $\mathrm{k}$ antagonist.

with the stable CAD group (6.1\% vs $3.2 \%, \mathrm{p}<0.001)$ due to MI and overall mortality.

The Kaplan-Meier (K-M) analysis for the primary endpoint (figure 1) did not indicate a significant difference between ACS and non-ACS patients (log-rank $\mathrm{p}=0.141)$. In contrast, the K-M curves (figure 2) for freedom of MACE in the ACS and non-ACS patient subgroups were different $(\log$-rank $\mathrm{p}<0.001)$, that is, patients with ACS have significantly higher MACE rates, which manifests itself in an early divergence of the K-M curves.

Nine-month MACE subgroup analyses

Additional $\chi^{2}$ analyses were conducted for 9-month MACE in a number of subgroups (figure 3), which did not reveal differences in terms of preloading $(\mathrm{p}=0.878)$, diabetes $(\mathrm{p}=0.995)$, dialysis $(\mathrm{p}=0.429)$ and region (Europe vs Asia, $\mathrm{p}=0.317)$. However, the presence of ISR in bare-metal stent (BMS) or DES at baseline led to numerically higher 9-month MACE rates $(8.3 \%$ vs $4.2 \%, \mathrm{p}=0.064)$ when compared with patients with de novo lesions. Finally, in the patient with stable CAD subgroup, the clinical event rates at 9 months were not different between patients who received 6 months of DAPT and those who had more than 6 months of DAPT (table 6). In these patients with stable CAD, there were no significant differences in terms of cardiovascular and lesion morphological risk factors at baseline between the short and long DAPT subgroups with the exception of

\begin{tabular}{lllll}
\hline \multicolumn{7}{l}{ Table 4} & Recommended duration of dual antiplatelet therapy during follow-up & & \\
\hline Variable & All patients & Stable CAD & ACS & $\begin{array}{c}\text { p Value } \\
\text { Stable CAD vs ACS }\end{array}$ \\
\hline No of patients & 2877 & 1793 & 1084 & - \\
\hline DAPT duration in months & $10.0 \pm 2.8$ & $9.4 \pm 2.9$ & $11.0 \pm 2.2$ & $<0.001$ \\
\hline 1 month, $n(\%)$ & $24(0.9)$ & $17(0.9)$ & $7(0.6)$ & $<0.001$ \\
\hline $1-3$ months, $n(\%)$ & $34(1.2)$ & $24(1.3)$ & $10(0.9)$ & \\
\hline $3-6$ months, $n(\%)$ & $12(0.4)$ & $8(0.4)$ & $4(0.4)$ & \\
\hline 6 months, $n(\%)$ & $503(17.5)$ & $416(23.2)$ & $87(8.0)$ & \\
\hline$>6-12$ months, $n(\%)$ & $282(9.8)$ & $210(11.7)$ & $72(6.6)$ & \\
\hline 12 months, $n(\%)$ & $1524(53.0)$ & $761(42.4)$ & $763(70.4)$ & \\
\hline$>12$ months, $n(\%)$ & $5(0.2)$ & $3(0.2)$ & $2(0.2)$ & \\
\hline Unknown status, $n(\%)$ & $493(17.1)$ & $354(19.7)$ & $139(12.8)$ & \\
\hline
\end{tabular}

ACS, acute coronary syndrome; CAD, coronary artery disease; DAPT, dual-antiplatelet therapy. 
Table 5 Clinical outcomes

\begin{tabular}{|c|c|c|c|c|}
\hline Variable & All patients & Stable CAD & ACS & $\begin{array}{l}\text { p Value } \\
\text { Stable CAD vs ACS }\end{array}$ \\
\hline No of patients & 2877 & 1793 & 1084 & - \\
\hline Patients with clinical follow-up at 9 months or early event, $\mathrm{n}(\%)$ & $2513(87.3)$ & $1566(87.3)$ & $947(87.4)$ & 0.986 \\
\hline Follow-up time (months) & $8.7 \pm 1.8$ & $8.6 \pm 1.9$ & $9.0 \pm 1.7$ & $<0.001$ \\
\hline Time to discharge, median (IQR) (days) & $\begin{array}{l}2.0(2.0) \\
(3.7 \pm 13.6)\end{array}$ & $\begin{array}{l}1.0(1.0) \\
(3.3 \pm 15.8)\end{array}$ & $\begin{array}{l}3(4.0) \\
(4.4 \pm 8.8)\end{array}$ & 0.021 \\
\hline Inhospital MACE, n (\%) & $41(1.4)$ & $11(0.6)$ & $30(2.8)$ & $<0.001$ \\
\hline Inhospital TLR, n (\%) & $14(0.5)$ & $5(0.3)$ & $9(0.8)$ & 0.039 \\
\hline Inhospital MI, n (\%) & $25(0.9)$ & $6(0.3)$ & $19(1.8)$ & $<0.001$ \\
\hline Inhospital cardiac death, $\mathrm{n}(\%)$ & $17(0.7)$ & $4(0.2)$ & $13(1.2)$ & 0.001 \\
\hline 9-month MACE, n (\%) & $108(4.3)$ & $50(3.2)$ & $58(6.1)$ & $<0.001$ \\
\hline $\begin{array}{l}\text { 9-month TLR } \\
\text { (re-PCl, CABG), n (\%) }\end{array}$ & $58(2.3)$ & $33(2.1)$ & $25(2.6)$ & 0.389 \\
\hline 9-month MI, n (\%) & $58(2.3)$ & $17(1.1)$ & $41(4.3)$ & $<0.001$ \\
\hline $\begin{array}{l}\text { 9-month } \\
\text { all-cause death, n (\%) }\end{array}$ & $38(1.5)$ & $14(0.9)$ & $24(2.5)$ & $<0.001$ \\
\hline 9-month accumulated definite/probable stent thrombosis, n (\%) & $17(0.7)$ & $9(0.6)$ & $8(0.8)$ & 0.424 \\
\hline Acute stent thrombosis, $\leq 24$ hours, $n(\%)$ & $9(0.4)$ & $4(0.3)$ & $5(0.5)$ & 0.372 \\
\hline Subacute stent thrombosis, $1-30$ days, $n(\%)$ & $1(0.0)$ & $0(0.0)$ & $1(0.1)$ & \\
\hline Late stent thrombosis, $\geq 30$ days, $\mathrm{n}(\%)$ & $7(0.3)$ & $5(0.3)$ & $2(0.2)$ & \\
\hline
\end{tabular}

ACS, acute coronary syndrome; CABG, coronary artery bypass grafting; CAD, coronary artery disease; MACE; major adverse cardiac events; MI, myocardial infarction; re-PCI, re-percutaneous coronary intervention; TLR, target lesion revascularisation.

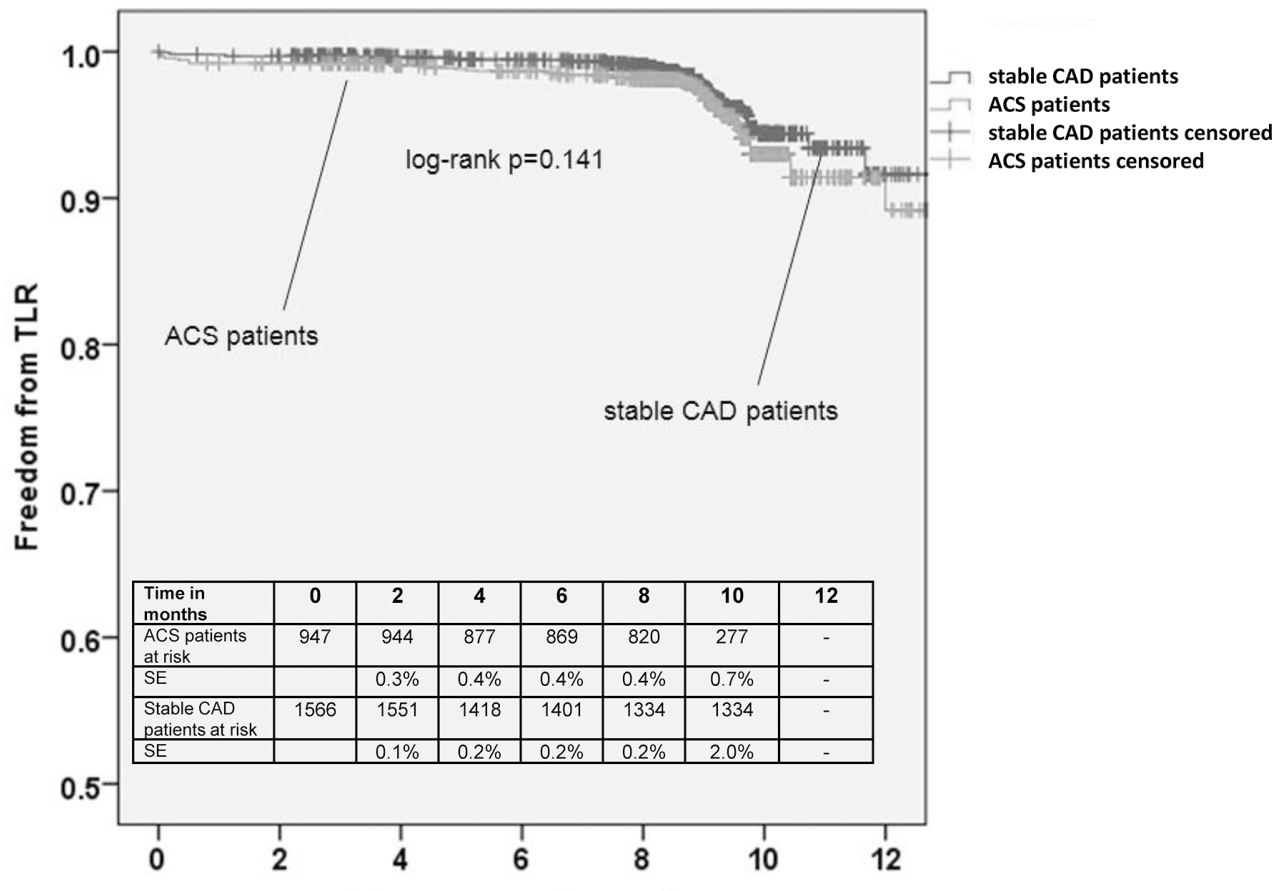

Time to event in months

Figure 1 Kaplan-Meier curve for freedom from TLR of patients with stable CAD and those with ACS. ACS, acute coronary syndrome; CAD, coronary artery disease; TLR, target lesion revascularisation. 


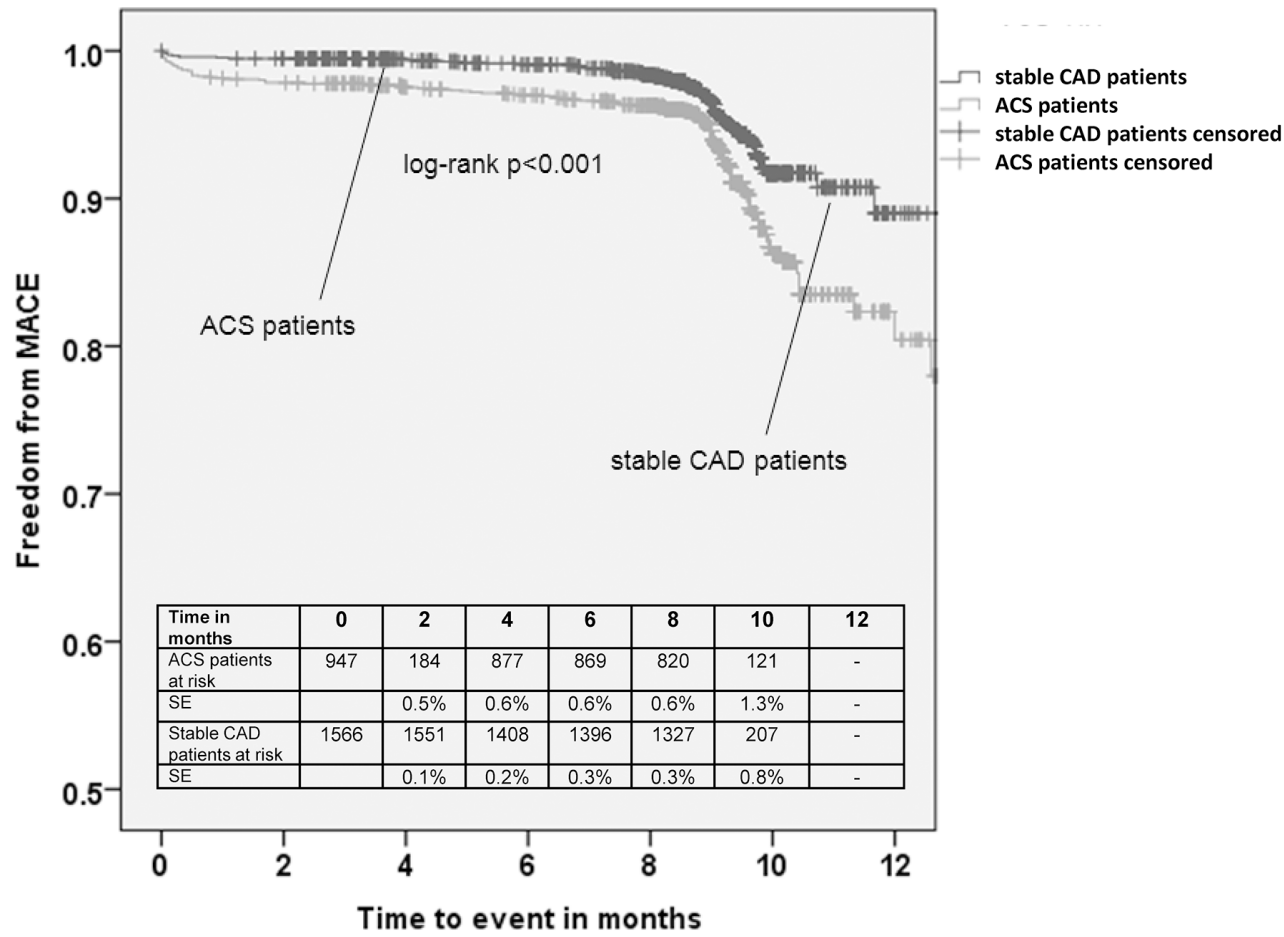

Figure 2 Kaplan-Meier curve for freedom from MACE of patients with stable CAD and those with ACS. ACS, acute coronary syndrome; CAD, coronary artery disease; MACE, major adverse cardiac events.

renal insufficiency, which was higher in the short DAPT subgroup ( $10.9 \%$ vs $4.9 \%$, $\mathrm{p}<0.001)$.

For comparison purposes, a subgroup of patients with a follow-up closer to 12 months (11.8 \pm 1.3 months) was also investigated. Their event rates were equally low with a stent thrombosis rate of $1.7 \%(2 / 115)$, MACE $4.3 \%$ $(5 / 115)$, TLR $1.7 \%(2 / 115)$, MI $2.6 \%(3 / 115)$ and all-cause death rate of $0.9 \%(1 / 115)$.
Bleeding complications

The accumulated rate of bleeding complications (Bleeding Academic Research Consortium (BARC) $1-5)$ was $1.8 \%(33 / 1793)$ in the stable CAD group and $2.4 \%(26 / 1084)$ in the ACS group $(p=0.306)$. There were no differences in bleeding frequency among patients who received different antithrombotic agents

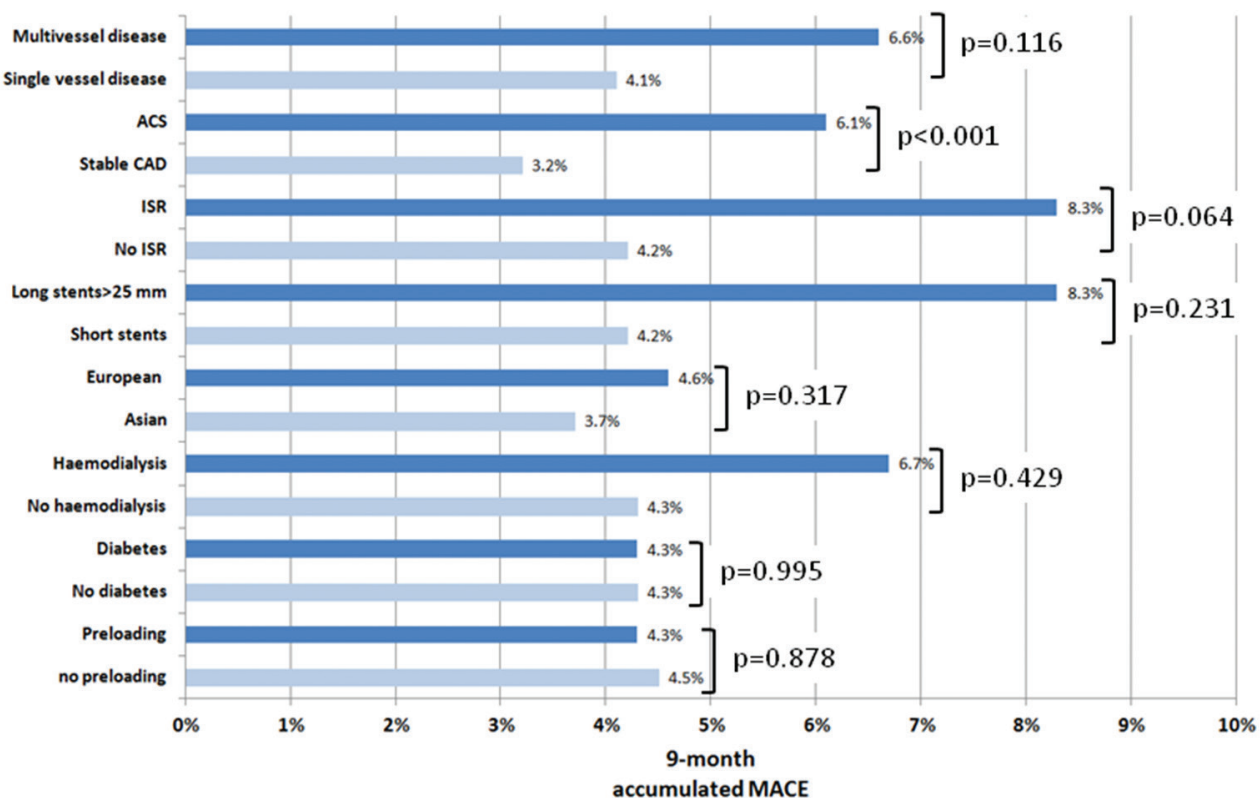

Figure 3 MACE rates in subgroups of the overall cohort. ACS, acute coronary syndrome; CAD, coronary artery disease; ISR, in-stent restenosis; MACE, major adverse cardiac events. 
in either group. However, patients who were on triple therapy in the stable CAD group had significantly more bleeding events when compared with those with DAPT only $(15.0 \%, 6 / 40$ vs $1.5 \%, 27 / 1753, \mathrm{p}<0.001)$. In the ACS group, triple therapy was also associated with a higher rate of bleeding events $(14.3 \%, 2 / 14$ vs $2.2 \%$, 24/1070; $\mathrm{p}=0.003$ ).

\section{DISCUSSION}

The analogue BMS backbone and the PF-SES ${ }^{6}$ had similar procedural/technical success rates. This can be rationalised with similar lesion crossing profiles of the crimped stents with identical stent architectures and identical delivery catheters. In terms of clinical outcomes, however, there is a pronounced clinical benefit of the sirolimus-probucol coating used in this study since the 9-month MACE and TLR rates $^{6}$ were significantly lower for the PF-SES (BMS analogue MACE 10.2\%, TLR 4.4\% vs PF-SES MACE $4.3 \%$ and TLR 2.3\%). A propensity score matching with the BMS database seems the only ethically feasible avenue to determine the exact added value of the sirolimus-probucol coating. This comparison of uncoated versus coated stents of identical design does not have the lustre of a clinical game changer but may certainly confirm the finding of the Norwegian Coronary Stent Trial (NORSTENT), that is, a significant difference in TLR rates.

Basically, the LEADERS-FREE trial $^{3}$ with the availability of the 2-year data ${ }^{12}$ could not demonstrate non-inferiority for BMS to DES as the default treatment strategy even in recognised indication niches such as patients with increased bleeding risks.

In reference to the ISAR-TEST 5 trial, the TLR rates in this registry were quite different, that is, $2.3 \%$ at 9 months versus $10.3 \%$ at 12 months in the ISAR trial despite a comparable all-comers population in both studies. One explanation for this finding is the angiographic follow-up in the ISAR-5 trial which was most likelyassociated with the recently reconfirmed 'occulo-stenotic reflex' or spontaneously conducted PCI without objective proof of ischaemia measurements, for example, fraction flow reserve. ${ }^{13}$ This, in turn, may have contributed to higher TLR rates in the ISAR-5 trial. However, this single-armed study included patients with long lesions and ISR, which were excluded in the ISAR-5 trial. Given that the lesion subsets in this registry appear to be more challenging to treat, our $2.3 \%$ TLR rate at 9 months fares well with previous findings considering the framework of a registry with potential under-reporting.

Iqbal et $a l^{14}$ reported MACE rates in an all-comers population treated with either ZES or everolimus-eluting stents (EES). At 9 months, the MACE rates were in the $6 \%-8 \%$ range without significant differences between EES and ZES. Because interstudy comparison is always plagued by methodological challenges, we can merely state that MACE rates in this study are comparable.

Colombo $e a^{15}$ conducted a single-armed study in an Italian all-comers population which demonstrated similar efficacy of a polymer-free sirolimus-eluting stent by usingorganic acids to modulate the drug release. They found target vessel failure rates of $10.1 \%(62 / 615)$ in the overall population. Despite the fact that the clinical event rates in this study are numerically lower, it allows the critical question whether diabetes can be considered as a true cardiovascular risk factor for increased MACE and TLR rates in modern DES. In this regard, our registry data did not reveal a significant difference in terms of MACE between diabetics and non-diabetics $(4.3 \%$ vs $4.3 \%$, $\mathrm{p}=0.995)$ which is in agreement with the ISAR-TEST 5 diabetic subgroup study ${ }^{9}$ and the findings of Colombo $e t$ $a .^{15}$

A more relevant question which seems to drive the current opinion is the debate whether DAPT can be discontinued if the need should arise, for example, an unplanned surgery. As pointed out by Stefanini et al, ${ }^{16}$ there is no class effect of modern DES, that is, different coating and release characteristics hinder the bridging of clinical benefits between devices of different design and coating technology.

Out of the myriad of potential explanatory variables in our $\chi^{2}$ analyses, only the ACS status $(\mathrm{p}<0.001)$ seems to have an impact on our 9-month MACE (figure 3).

Table 6 Nine-month clinical outcomes in patients with stable CAD on short vs long DAPT

\begin{tabular}{|c|c|c|c|c|}
\hline Variable & All patients & $\begin{array}{l}\text { Less or equal to } \\
6 \text { months of DAPT }\end{array}$ & $\begin{array}{l}\text { Longer than } \\
6 \text { months of } \\
\text { DAPT }\end{array}$ & $\begin{array}{l}\text { p Value } \\
\text { long vs short DAPT }\end{array}$ \\
\hline No of patients & 1566 & 384 & 1182 & - \\
\hline 9-month MACE, n (\%) & $50(3.2)$ & $12(3.1)$ & $38(3.2)$ & 0.931 \\
\hline $\begin{array}{l}\text { 9-month TLR } \\
\text { (re-PCI, CABG), n (\%) }\end{array}$ & $33(2.1)$ & $8(2.1)$ & $25(2.1)$ & 0.970 \\
\hline 9-month death all causes, $n(\%)$ & $14(0.9)$ & $4(1.0)$ & $10(0.8)$ & 0.723 \\
\hline $\begin{array}{l}\text { 9-month accumulated definite/probable stent thrombosis, } \\
\mathrm{n}(\%)\end{array}$ & $9(0.6)$ & $3(0.8)$ & $6(0.5)$ & 0.538 \\
\hline
\end{tabular}

CABG, coronary artery bypass grafting; CAD, coronary artery disease; DAPT, dual-antiplatelet therapy; MACE, major adverse cardiac events; MI, myocardial infarction; re-PCl, re-percutaneous coronary intervention; TLR, target lesion revascularisation. 
Established risk factors such as diabetes, stent length or multivessel disease do not seem to increase MACE in patients with ACS and those with stable CAD. Because of the non-polymer matrix, the PF-SES used in this assessment is transformed into a BMS once the sirolimusprobucol matrix is fully released. Recently published meta-analyses by D'Ascenzo $e t a l^{17}$ and Savarese $e t a l^{18}$ investigated the effect of DAPT duration in first-generation and second-generation DES. D'Ascenzo et al concluded that DAPT for up to 6 months can be justified in patients receiving EES and ZES. However, the observed decreased risk of major bleeding must be balanced at a higher risk of MI if the shorter DAPT is chosen. ${ }^{17}$ Savarese et $a l^{18}$ reported that prolonged DAPT did not reduce mortality rates. Our results, nevertheless, indicate that a shorter DAPT duration up to 6 months did not show higher event rates in the elective patient cohort. Elective patients who received up to 6 months of DAPT had comparable rates for MACE (3.1\% vs 3.2\%, p=0.931) and TLR (2.1\% vs $2.1 \%, \mathrm{p}=0.970)$. We also investigated the 9-month MACE rates of patients with stable CAD in subgroups of $0-3$, 3-6s, 6-12 months and beyond 12 months which yielded $5.4 \%, 2.9 \%, 3.3 \%$ and $0.0 \%$, respectively, whereas patients with unknown DAPT duration had a 9-month MACE rate of $3.1 \%$. In this analysis we could not detect a difference among these subgroups $(\mathrm{p}=0.937)$. Despite the fact that this analysis was not powered to detect differences, this finding warrants further investigations. Mauri $e t a l^{2}$ who concluded that longer DAPT had clinical benefits for patients with stable CAD and those with ACS could not be demonstrated in our study since our follow-up horizon was substantially shorter than the one reported in the DAPT study.

The recently published results of the NORSTENT study ${ }^{19}$ revealed that DES implantations had no benefit over BMS in terms of the combined rate of all-cause mortality and non-fatal MI ( $16.6 \%$ vs $17.1 \%, \mathrm{p}=0.66)$ within a follow-up period of 6 years. In contrast, the 6-year TLR rates were clearly in favour of DES angioplasty $(16.5 \%$ vs $19.8 \%, \mathrm{p}<0.001)$ which is in agreement with our results and the findings of the uncoated analogue BMS backbone. ${ }^{6}$

Finally, a careful ramification based on our findings can be made relative to balancing the bleeding risks and DAPT duration. As proposed by Yeh et $a l^{20}$ a benefit:risk ratio for extended DAPT could be quantified on a 'penalty' point system. In future subgroup analyses of this large-scale study, the application of this proposed rating system is highly desirable.

\section{Limitations}

Intrinsic to an observational study of this size, the less stringent control in terms of data collection and study monitoring may have introduced event under-reporting. Furthermore, the follow-up rate of $87.3 \%$ is not ideal; however, the 2513 patients with a clinical follow-up provided a wealth of data for meaningful subgroup analyses. Moreover, patients with 9-month follow-up did not have an 'easier' cardiovascular risk profile when compared with those lost to follow-up, which would have skewed the clinical results. We suspect that this large patient base may compensate for some of the inaccuracies that were introduced by the aforementioned lack of $100 \%$ on-site monitoring. Another shortcoming of our work is the fact that reliable dyslipidemia data could not be obtained and the smoking status was not determined at baseline. This established risk factor would have been very desirable for our exploratory logistic regression analyses. Although we could not detect increased rates of MACE in the absence of preloading or shorter DAPT in our data set, our findings are hypothesis generating and do, therefore, not replace a properly designed non-inferiority trial with primary endpoint ST rate as described by Waliszewski and Rittger ${ }^{21}$ with patient numbers in the 2000-8000 patient range per treatment group.

\section{CONCLUSION}

PF-SES angioplasty was safe and effective in ACS patients with low rates of TLR and MACE which are comparable to reports of other polymer-free DES technologies. Patients who were not able to receive antiplatelet preloading do not have higher rates of TLR or MACE at 9 months. Established risk factors such as diabetes, lesion length, vessel diameter or presence of $\mathrm{B} 2 / \mathrm{C}$ lesions do not seem to increase TLR in patients with ACS and those with stable CAD. The impact of shortened DAPT remains to be speculative; however, stable CAD patients with a DAPT duration of up to 6 months did not have higher TLR rates when compared with those with DAPT durations longer than 6 months.

\section{Author affiliations}

${ }^{1}$ Kardiologie, Campus Virchow-Klinikum Charité, Berlin, Germany

${ }^{2}$ Department of Cardiology, University Hospital Královské Vinohrady, Prague, Czech Republic

${ }^{3}$ Department of Medical Scientific Affairs, B. Braun Melsungen AG, Berlin, Germany ${ }^{4}$ Ambulantes Herzzentrum Kassel, Kassel, Germany

${ }^{5}$ Department of Kardiologie, Sudharz Klinikum Nordhausen gGmbH, Nordhausen, Thüringen, Germany

${ }^{6}$ Department of Cardiology, SUSCCH a.s., Banská Bystrica, Slovakia

${ }^{7}$ Cardiocentre of Teaching Hospital of J.A. Reiman, Prešov, Slovakia

${ }^{8}$ Department of Kardiologie, Elblandklinikum Riesa, Riesa, Germany

${ }^{9}$ Department of Kardiologie, Helmut-G.-Walther-Klinikum Lichtenfels, Lichtenfels, Germany

${ }^{10}$ Division of Cardiology, Chonnam National University Hospital, Gwangju, Republic of Korea

${ }^{11}$ Department of Cardiology, Gil Hospital, Gachon University, Incheon, Republic of Korea

${ }^{12}$ Division Cardiology, Department of Medicine, University Malaya Medical Centre, Kuala Lumpur, Malaysia

${ }^{13}$ Klinik für Kardiologie, Angiologie, Pneumologie, Klinikum Esslingen, Esslingen, Baden-Württemberg, Germany

Acknowledgements The authors express their sincere thanks to Dr Ralf Degenhardt at the Cardiovascular Center in Rotenburg, Germany for his essential statistical expertise. Furthermore, the authors would like to express their gratitude to the following Medical AffairsTeam members Denny Herberger (Germany), Dr Ghislaine Martin and Ms Aude Michaud (France), Dr Ricard Rosique (Spain), Ms Zoey Hooi (Malaysia) and Ms Yoonmi Lee (South Korea) for their regulatory and logistic support to conduct this study. 
Contributors FK, ML, MWW and MB contributed to conception, design, data analysis and interpretation. FK, MWW and ML drafted and critically revised the article. All authors gave final approval of the version to be published.

Competing interests FK received lecturing fees, and MWW and MB served full time employment at the Department of Medical Scientific Affairs, B. Braun Melsungen AG.

Ethics approval Prior to patient recruitment all ethics votes were obtained from relevant national or local ethics committees. In France, this non-interventional study was nationally approved by the Comité Consultative sur le Traitement de I'Information en matière de Recherche dans le domaine de la Santé (CCTIRS dossier no. 14.613) and the Commission Nationale de l'informatique et des Libertés (CNIL, demande d'autorisation $\mathrm{n}^{\circ}$ 915019).

Provenance and peer review Not commissioned; externally peer reviewed.

Data sharing statement All data can be shared in the public interest.

Open Access This is an Open Access article distributed in accordance with the Creative Commons Attribution Non Commercial (CC BY-NC 4.0) license, which permits others to distribute, remix, adapt, build upon this work non-commercially, and license their derivative works on different terms, provided the original work is properly cited and the use is non-commercial. See: http://creativecommons.org/ licenses/by-nc/4.0/

C Article author(s) (or their employer(s) unless otherwise stated in the text of the article) 2017. All rights reserved. No commercial use is permitted unless otherwise expressly granted.

\section{REFERENCES}

1. Palmerini T, Benedetto U, Biondi-Zoccai G, et al. Long-term safety of drug-eluting and bare-metal stents: evidence from a comprehensive network meta-analysis. J Am Coll Cardiol 2015;65:2496-507.

2. Mauri L, Kereiakes DJ, Yeh RW, et al. Twelve or 30 months of dual antiplatelet therapy after drug-eluting stents. $N$ Engl J Med Overseas Ed 2014;371:2155-66.

3. Urban P, Meredith IT, Abizaid A, et al. Polymer-free drug-coated coronary stents in patients at high bleeding risk. N Engl J Med 2015;373:2038-47.

4. Massberg S, Byrne RA, Kastrati A, et al. Polymer-free sirolimusand probucol-eluting versus new generation zotarolimus-eluting stents in coronary artery disease: the Intracoronary stenting and angiographic results: test efficacy of sirolimus- and probucol-eluting versus zotarolimus-eluting stents (ISAR-TEST 5) trial. Circulation 2011;124:624-32.

5. Cutlip DE, Windecker S, Mehran R, et al. Clinical end points in coronary stent trials: a case for standardized definitions. Circulation 2007;115:2344-51.

6. Leschke M, Waliszewski M, Pons M, et al. Thin strut bare metal stents in patients with atrial fibrillation: is there still a need for BMS? Catheter Cardiovasc Interv 2016;88:358-66.

7. Kufner S, Sorges J, Mehilli J, et al. Randomized trial of polymerfree sirolimus- and probucol-eluting stents versus durable polymer zotarolimus-eluting stents: 5-year results of the ISARTEST-5 trial. JACC Cardiovasc Interv 2016;9:784-92.
8. Colleran R, Kufner S, Harada Y, et al. Five-year follow-up of polymerfree sirolimus- and probucol-eluting stents versus new generation zotarolimus-eluting stents in patients presenting with st-elevation myocardial infarction. Catheter Cardiovasc Interv 2017;89:367-74.

9. Harada Y, Colleran R, Kufner S, et al. Five-year clinical outcomes in patients with diabetes mellitus treated with polymer-free sirolimusand probucol-eluting stents versus second-generation zotarolimuseluting stents: a subgroup analysis of a randomized controlled trial. Cardiovasc Diabetol 2016;15:124.

10. Windecker S, Kolh P, Alfonso F, et al. 2014 ESC/EACTS guidelines on myocardial revascularization: the task force on myocardial revascularization of the European Society of Cardiology (ESC) and the European Association for Cardio-Thoracic Surgery (EACTS)developed with the special contribution of the European Association of Percutaneous Cardiovascular Interventions (EAPCI). Eur Heart J 2014;35:2541-619.

11. Wöhrle J, Zadura M, Möbius-Winkler S, et al. SeQuentPlease World Wide Registry: clinical results of SeQuent please paclitaxel-coated balloon angioplasty in a large-scale, prospective registry study. J Am Coll Cardiol 2012;60:1733-8.

12. Garot P, Morice MC, Tresukosol D, et al. 2-year outcomes of high bleeding risk patients after polymer-free drug-coated stents. J Am Coll Cardiol 2017;69:162-71.

13. Nakamura M, Muramatsu $\mathrm{T}$, Yokoi $\mathrm{H}$, et al. Outcomes of the largest multi-center trial stratified by the presence of diabetes mellitus comparing sirolimus-eluting stents (SES) and paclitaxel-eluting stents (PES) in patients with coronary artery disease. The Japan drug-eluting stents evaluation: a randomized trial (J-DESsERT). Cardiovasc Interv Ther 2015;30:103-14.

14. Iqbal J, Serruys PW, Silber S, et al. Comparison of zotarolimusand everolimus-eluting coronary stents: final 5-year report of the RESOLUTE all-comers trial. Circ Cardiovasc Interv 2015;8(6):e002230.

15. Colombo A, Godino C, Donahue M, et al. One-year clinical outcome of amphilimus polymer-free drug-eluting stent in diabetes mellitus patients: insight from the ASTUTE registry (AmphilimuS iTalian mUlticenTre rEgistry). Int J Cardiol 2016;214:113-20.

16. Stefanini GG, Behan M, Valgimigli M, et al. Will LEADERS-FREE change my practice? A randomised double-blind comparison of the BioFreedom ${ }^{\mathrm{TM}}$ drug-coated stent vs. the Gazelle ${ }^{\mathrm{TM}}$ bare metal stent in patients at high bleeding risk using a short (1 month) course of dual antiplatelet therapy. Eurolntervention 2016;12:798-800.

17. D'Ascenzo F, Moretti C, Bianco M, et al. Meta-analysis of the duration of dual antiplatelet therapy in patients treated with secondgeneration drug-eluting stents. Am J Cardiol 2016;117:1714-23.

18. Savarese G, Savonitto S, Lund LH, et al. Efficacy and safety of prolonged dual antiplatelet therapy: a meta-analysis of 15 randomized trials enrolling 85265 patients. Eur Heart J Cardiovasc Pharmacother 2016;2:218-28.

19. Bønaa $\mathrm{KH}$, Mannsverk J, Wiseth $\mathrm{R}$, et al. Drug-eluting or bare-metal stents for coronary artery disease. N Engl J Med 2016;375:1242-52.

20. Yeh RW, Secemsky EA, Kereiakes DJ, et al. Development and validation of a prediction rule for benefit and harm of dual antiplatelet therapy beyond 1 year after percutaneous coronary intervention. JAMA 2016;315:1735-49.

21. Waliszewski M, Rittger H. Surrogate and clinical endpoints in interventional cardiology: are statistics the brakes? Ther Adv Cardiovasc Dis 2016;10:314-26. 